\title{
Review
}

\section{Current concepts concerning the etiology of essential hypertension}

\author{
James Conway, M.D., Ph.D.* \\ Ann Arbor, Mich.
}

\begin{abstract}
Qince hypertension was identified as a $N$ distinct disease at the turn of the century, there have been many occasions when it seemed likely that its cause had been found, but each time it has proved illusory, and at present no one theory seems more promising than another. Some investigators indeed believe that ultimately the disease will be attributed to multiple interrelated factors as expressed in the mosaic theory of Page. ${ }^{1}$ Others regard hypertension not as a disease, but as an expression of a graded physical characteristic. High blood pressure would then be analogous to exceptional height.
\end{abstract}

\section{Population studies}

The theory that hypertension is not a specific disease, forcefully presented by Pickering, ${ }^{2}$ is based upon three findings in surveys of blood pressure in the human population: (1) the distribution of blood pressure values in the population, (2) the effect of age upon blood pressure, and (3) the similarity in blood pressure levels among close relatives. Essential to this theory is the smooth distribution curve of blood pressure in the population. The blood pressure rises with age, and the slight skew in the distribution curve becomes more pronounced with increasing age, but a departure from this distribution pattern which would indicate the emergence of a group of subjects with a "disease" hypertension cannot be demonstrated at any stage. Attempts have been made to show that the change in the form of the distribution curve with age conceals a group of patients with essential hypertension, ${ }^{3}$ but it has been explained that technical deficiencies in blood pressure recording which are caused by the tendency to aggregate readings about the nearest ten-millimeter mark are responsible for some irregularities in the distribution curves. This pitfall can be avoided, and recent studies show that a break in the blood pressure distribution curve cannot then be demonstrated. ${ }^{4}$ Furthermore, the separation of normal subjects from those with hypertension on the basis of blood pressure readings alone is shown to be artificial by the gradual increase in mortality experience from below "normal" to the highest levels as demonstrated by life insurance data. ${ }^{5}$

A rise in blood pressure with age has been a consistent finding from the earliest population surveys, but the crucial evidence required by Pickering's theory is that the rise in pressure be found in the majority of individuals. Follow-up studies by Stamler ${ }^{6}$ show this trend in only approximately one half the population, and data from life insurance companies demonstrate it in only one third of the population. ${ }^{7}$ Further evidence eventually will clarify this point, but

From the Department of Internal Medicine, University of Michigan Medical Center, Ann Arbor, Mich.

Based on a lecture given at the Postgraduate School of Medicine, University of Texas, Houston, Tex.

Received for publication Dec. 3, 1962.

*Established Investigator, American Heart Association. 
data of this type are exceedingly difficult to obtain since blood pressure is so readily affected by environmental forces.

These epideniological studies, however, demonstrate that the process which results in an elevation of pressure, whether this be termed a disease or not, is operative at a much earlier age than that at which patients are commonly seen in the clinic. By that time, the effects of sustained pressure on the vascular system may be confused with its cause.

\section{Neurogenic theory}

Psychological factors readily affect blood pressure, but the increase in vascular resistance which is characteristic of established essential hypertension is not observed under nervous stress. Labile hypertension results from an increase in cardiac output, and the condition is readily reversed by bed rest. ${ }^{8}$ However, Brod $^{9}$ has suggested that the central regulation of the circulation is abnormal in hypertension, and that the distribution of blood flow in hypertension resembles that obtained in normal subjects during the stress of noxious stimuli or the preparation for exercise. There is also some evidence $^{10}$ that in patients who undergo transient elevation of pressure there is a tendency to eventually develop essential hypertension.

It is possible, therefore, that neurogenic mechanisms, activated perhaps by psychological or personality traits, may be concerned in the initiation of hypertension.

In established hypertension, however, the motor pathway for neurogenic hypertension, the sympathetic nervous system, is not demonstrably overactive. This has been shown by measurement of the effect of the sympathetic nervous system on blood vessels ${ }^{11}$ and on the excretion of catecholamines. $^{12}$ Both these methods, incidentally, can detect modest changes in sympathetic nervous activity when such changes occur in normal subjects. Since, in hypertension, autonomic blocking agents do not reduce the peripheral resistance to normal, it is unlikely that neurogenic factors are primarily responsible for the elevation of pressure.

This is not intended to convey that the nervous system plays no role in hypertension; its activity may contribute to or ag- gravate the severity of the disease. Many hypertensive patients are insecure and apprehensive and have difficulty in asserting themselves. These patterns may not be related in any way to the cause of hypertension, but may be the result of it. So much popular literature is devoted to the woes of this disease that it is not surprising that many hypertensive persons are acutely concerned about themselves. The ability of reassurance and suggestion, therefore, to lower blood pressure ${ }^{13}$ should not be ignored as a useful adjunct to treatment.

\section{Renal cause}

Although anatomic involvement of the renal vessels may not be demonstrable in the earliest phases of hypertension, ${ }^{14}$ renal vascular changes are prominent and almost universal in later stages. A reduction in renal blood flow is also the most prominent physiologic finding in essential hypertension at all stages..$^{15}$ It is almost superfluous to mention that the most common cause of secondary hypertension is renal disease: chronic nephritis, pyclonephritis, or renovascular disease; and in systemic collagen diseases the emergence of hypertension signals renal involvement. Yet it is important to remember that operative mechanisms responsible for the elevation of blood pressure in these diseases are unknown. It seems certain also that the kidneys play a central role in the mechanisms concerned with the maintenance of normal pressure, either by clearing the blood of vasoconstricting materials or by secreting a pressor substance. The recently recognized association between the renin-angiotensin system and the production of aldosterone ${ }^{16}$ demonstrates that the action of angiotensin may be more complex than was originally envisaged, and levels of blood inadequate for its vasoconstrictive action may have physiologic effects. Furthermore, reports of detectable levels of renin or angiotensin in the blood have been made in both essential and renovascular hypertension. ${ }^{17}$

No differences, therefore, in any physiologic characteristics have been demonstrated between essential hypertension and the secondary forms of the disease, with the exception of pheochromocytoma. This suggests either that these conditions have a common etiology or that they utilize a 
common final mechanism. The kidney remains the most likely suspect as the cause of hypertension.

\section{Endocrine or metabolic causes}

Much circumstantial evidence has been accumulated to link disorders of sodium, and perhaps water, metabolism to hypertension. Rigid restriction of the intake of sodium will lower blood pressure, and a very high intake of sodium may raise it. ${ }^{18}$ Hypertensive patients appear to consume more sodium than do normal subjects, ${ }^{19}$ and the concentration of sodium in the walls of their blood vessels is abnormally high ${ }^{20}$ In hypertension, the kidney handles sodium abnormally; it excretes a load of sodium more rapidly than normal, ${ }^{21}$ and it may respond more slowly to a restriction of sodium, but this is not certain. ${ }^{22}$ Although the evidence for an increased serum sodium concentration in hypertension is contradictory, and exchangeable sodium is normal in uncomplicated hypertensive disease, it has been shown recently that the turnover of labeled sodium is prolonged in hypertension. ${ }^{23}$

Primary aldosteronism and Cushing's disease produce hypertension which may be indistinguishable from essential hypertension, and Genest ${ }^{24}$ has long maintained that there is an increase in mineralocorticoid excretion in essential hypertension. There is, however, no clear evidence for overactivity of the adrenal cortex in uncomplicated essential hypertension. ${ }^{25}$ The antihypertensive effect of diuretic agents adds to the likelihood that a derangement of salt. and water balance is operating in hypertension. On the other hand, it has not been possible to link the therapeutic effect of diuretic agents to the loss of sodium; however, it seems likely that some other effect of the sustained diuretic action is responsible for the fall in blood pressure, since other diuretic agents (notably spironolactone) also lower blood pressure. It will be recalled that it has not been possible to determine that precise changes in electrolyte metabolism or distribution were responsible for the effectiveness of the lowsodium diet. ${ }^{26}$

Finally, there is the evidence in man with complete renal failure that hypertension develops only when the patient gains so- dium or water. ${ }^{27}$ This seems analogous to toxemia of pregnancy, which is associated with an increase in body water, ${ }^{28}$ possibly in excess of sodium, and which is preventable by control of the excessive accumulation of fluid.

In the etiology of hypertension, abnormalities of sodium or water metabolism are suspect at the present time, but, again, we do not know the actual nature of the derangement or the means by which it could lead to an increase in peripheral resistance.

\section{A vascular abnormality}

The increase in peripheral resistance is, perhaps, the only fart that has remained unchallenged in the changing fortunes of the theories of hypertension. It is strange, therefore, that the function of peripheral blood vessels in this disease has received such scant attention.

It is sobering to find that it has never been possible to demonstrate an increase in vascular smooth muscle tone to account for the increase in resistance in hypertension. There is, however, considerable evidence that the arterial vessels function abnormally. The blood vessels of hypertensive patients can be shown to respond abnormally to vasoçonstrictor stimuli, ${ }^{29}$ and this has been shown to apply in experimental hypertension. Although this fact is sometimes questioned, a review of the literature reveals that whenever the direct response of a particular vascular bed has been investigated, increased reactivity has been readily demonstrable, ${ }^{30}$ whereas it may not be found after intravenous administration of a drug.

It has been shown that in essential hypertension the dilatation of the blood vessels in response to supramaximal vasodilator stimuli is reduced. ${ }^{31,32}$ The resistance to flow in the forearm after prolonged ischemia or supramaximal doses of vasodilator drugs is found to be greater in hypertensive than in normal persons. There appears, therefore, to be an element of resistance in hypertension which is probably not related to the ordinary activity of vascular smooth muscle. Microradiographic studies have also demonstrated diffuse narrowing in caliber of injected submucosal vessels in hypertension. ${ }^{33}$ The muscle fibers in their relaxed state, therefore, may differ in length from 
normal, or there may be some other anatomic change in the blood vessels.

It has been of special interest that the various types of secondary hypertension, chronic glomerulonephritis, renovascular disease, or aldosteronism, have each demonstrated the same inability to relax fully during reactive hyperemia, again suggesting that these several conditions may affect the blood vessels in the same way. ${ }^{32}$

\section{Conclusion}

To form an opinion concerning the etiology of essential hypertension from the present evidence is difficult, not because of the paucity of facts, but rather because of the apparently equal strength of the rival theories. The possibility which would account for the greatest number of known facts is that essential hypertension is primarily a renal disease which results, either directly or through the intervention of the adrenal cortex, in the abnormal handling of sodium, water or, possibly, some other electrolyte. This, in turn, leads to an increase in peripheral resistance, either actively through changes in the contractile properties of the vascular smooth muscle or passively by decreasing the lumen of the vessels, perhaps by cellular swelling as suggested by Tobian. ${ }^{20}$ Since this speculation involves a chain of events, it would seem reasonable to propose that there may be a variety of causative mechanisms affecting the system at different points, and/or that there is probably more than one means of producing the postulated metabolic abnormality.

\section{REFERENCES}

1. Page, I. H.: The mosaic theory of hypertension, in Bock, K. D., and Cottier, P. T., editors: Essential Hypertension, Berlin, 1960, Springer Verlag, p. 1.

2. Pickering, G. W.: High blood pressure, London, 1955, Churchill.

3. Platt, R.: The nature of essential hypertension, in Bork and Cottier, ${ }^{1}$ p. 39.

4. Lowe, C. R., and McKeown, T.: Arterial pressure in an industrial population and its bearing on the problem of essential hypertension, Lancet 1 : $1686,1962$.

5. Society of Actuaries: Build and Blood Pressure Study, New York 1960, Mallon, Inc.

6. Stamler, J., Lindberg, H. A., Berkson, D. M., Shaffer, A., Miller, W., and Poindexter, A.: Epidemiological analysis of hypertension and hypertensive disease in the labor force of a Chicago utility company, Proc. High Blood Press. Council, Am. Heart Assoc. 7:23, 1958.
7. Trends in blood pressure of individuals, Metro, politan Life Ins. Statistical Bull. 42:4, May1961.

8. Eich, R. H., Peters, R. J., Cuddy, R. P. Smulyan, H., and Lyons, R. H.: The hemodynamics in labile hypertension, Am. Heart $\mathrm{J}$. 63:188, 1962 .

9. Brod, J.: Essential hypertension: hemodynamic observations with a bearing on its pathogenesis, Lancet 2:773, 1960 .

10. Levy, R. L., Hillman, C. C., Stroud, W. D., and White, P. D.: Transient hypertension: its significance in terms of later development of sustained hypertension and cardiovascular-renal diseases, J.A.M.A. $126: 829,1944$.

11. Prinzmetal, M., and Wilson, C.: The nature of the peripheral resistance in arterial hypertension, with special reference to the vasomotor system, J. Clin. Invest. 19:25, 1940.

12. Von Euler, U. S., Hillner, S., and Purkhold, A.: Excretion of noradrenaline in urine in hypertension, Scandinav. J. Clin. \& Lab. Invest. 6:54, 1954.

13. Goldring, W., Chasis, H., Schreiner, G. E., and Smith, H. W.: Reassurance in the management of benign hypertensive disease, Circulation $14: 260,1956$.

14. Sommers, S. C., Relman, A. S., and Smithwick, R. H.: Histologic studies of kidney biopsy specimens from patients with hypertension, Am. J. Path. 34:685, 1958

15. Goldring, W., and Chasis, H.: Hypertension, New York, 1954, Commonwealth Fund.

16. Davis, J. O., Hartroft, P. M., Titus, E. O., Carpender, C. C. J., Ayers, C. R., and Spiegel, $H$. E.: The role of the renin-angiotensin system in the control of aldosterone secretion, J. Clin. Invest. $41: 378,1962$.

17. Helmer, O. M., and Judson, W. E.: The presence of vasoconstrictor activity in renal vein plasma in patients with arterial hypertension, Proc. High Blood Press. Council, Am. Heart Assoc. 8:38, 1960 .

18. Perera, G. A., and Blood, D. W.: The relation ship of sodium chloride to hypertension, J. Clin. Invest. 26:1109, 1947.

19. Dahl, L. K., and Love, R. A.: Etiological role of sodium chloride intake in essential hypertension in humans, J.A.M.A. 164:397, 1957.

20. Tobian, L., and Binion, B. S.: Tissue cations and water in arterial hypertension, Circulation 5:754, 1952.

21. Cottier, P. T., Weller, J. M., and Hoobler, S. W.: Sodium chloride excretion following salt loading in hypertensive subjects, Circulation 18:196, 1958 .

22. Renwick, R., Robson, J. S., and Stewart, C. P.: Observations upon the withdrawal of sodium chloride from the diet in hypertensive and normotensive individuals, J. Clin. Invest. 34:1037, 1955.

23. Dahl, L., Smilay, M., Silver, L., and Spraragen, S.: Evidence for a prolonged biological half-life of $\mathrm{Na}^{22}$ in patients with hypertension, Circulation Res. 10:313, 1962.

24. Genest, J., Lemieux, G., Davignon, A., Koiw, E., Nowaczynski, W. J., and Steyermark, P.: 
Human arterial hypertension: a state of mild chronic hyperaldosteronism? Science 123:503, 1956.

25. Laragh, J. H., Ulick, S., Januszewicz, V., Kelly, W. G., and Lieberman, S.: Electrolyte metabolism and aldosterone secretion in benign and malignant hypertension, J. Clin. Invest. 39:1091, 1960.

26. Dole, V. P., Dahl, L. K., Cotzias, G. C., Eder, H. A., and Krebs, M. E.: Dietary treatment of hypertension. Clinical and metabolic studies of patients on the rice-fruit diet, J. Clin. Invest. 29:1189, 1950 .

27. Merrill, J. P., Giordano, C., and Heetderks, D. R.: The role of the kidney in human hypertension, Am. J. Med. 31:931, 1961.

28. Macgillivray, I.: Water and electrolyte metabolism, Amsterdam, 1961, Elsevier Publishing Company, p. 124.
29. Doyle, A. E., Fraser, J. R. E., and Marschall, J.: Reactivity of forearm vessels to vasoconstrictor substances in hypertensive and normotensive subjects, Clin. Sc. 18:441, 1959.

30. Bárány, F. B., and James, P.: The sensitivity to 1-noradrenaline of patients with high blood pressure, Clin. Sc. 18:513, 1959.

31. Folkow, B., Grimby, G., and Thulcsius, O.: Adaptive structural changes in the vascular walls in hypertension and their relation to the control of peripheral resistance, Acta physiol. scandinav. 255:272, 1959.

32. Conway, $\mathrm{J}:$ : A vascular abnormality in hypertension: a study of blood flow in the forearm, Circulation (in press).

33. Short, D. S., and Thomson, A. D.: The arteries of the small intestine in systemic hypertension, J. Path. \& Bact. 78:321, 1959. 